\title{
Retinoid-induced ossification of the posterior longitudinal ligament
}

\author{
David R. Pennes, M.D. ${ }^{1}$, William Martel, M.D. ${ }^{1}$, and Charles N. Ellis, M.D. ${ }^{2,3}$ \\ ${ }^{1}$ Departments of Radiology and ${ }^{2}$ Dermatology, University of Michigan Medical Center \\ ${ }^{3}$ Dermatology Service, Ann Arbor Veterans Administration Medical Center, Ann Arbor, Michigan, USA
}

\begin{abstract}
Vitamin A and its synthetic congeners are known to produce a variety of skeletal abnormalities in patients on prolonged treatment with these medications. Two patients are described who developed posterior longitudinal ligament ossification following treatment with the synthetic retinoid 13-cis-retinoic acid. In both cases, this finding became apparent after other retinoid-induced skeletal abnormalities were observed and was less marked than the ossification of the anterior longitudinal ligament. Although spinal cord compression did not occur in our patients, patients on long-term retinoid therapy should be carefully observed for this complication.
\end{abstract}

Key words: Ossification of the posterior longitudinal ligament - Idiopathic skeletal hyperostosis Retinoid - Vitamin A

Synthetic and natural forms of vitamin A, collectively known as retinoids, are now recognized to produce a variety of skeletal manifestations when administered for prolonged periods $[3,6,9,11]$. These skeletal manifestations consist chiefly of periosteal linear bone apposition paralleling the diaphyses of the bones of the appendicular skeleton [3], or discrete hyperostoses arising from the promontories or ends of bones [9 11]. Ossification of the spinous ligaments, in particular the anterior longitudinal ligament $[6,11]$ and ligamenta flava [6], has also been described. We present two patients who developed ossification of the posterior longitudinal ligament (OPLL) during therapy with the synthetic retinoid 13-cis-retinoic acid. To our

Address reprint requests to: William Martel, M.D., Department of Radiology, Box 13, University of Michigan Hospitals, 1405 E. Ann Street, Ann Arbor, MI 48109, USA knowledge, this observation has not been described previously.

These two individuals are from a group of nine patients being followed at our institution on chronic retinoid therapy for treatment of congenital disorders of keratinization. One patient (Case 1) was described previously by other authors in another context [11] before seeking care at our institution. Early hyperostoses at other skeletal locations were previously described in our Case 2 [4].

\section{Case reports}

Case 1

After two years of treatment with 13-cis-retinoic acid for severe ichthyosis, a 32-year-old woman developed multiple hyperostoses in both the appendicular and axial skeleton, with pain and limitation of motion of the cervical and lumbar spine [11]. The severity of the dermatosis and the elinical improvement with therapy prompted the continuance of intermittent courses of retinoid therapy over the next two years. Films obtained following the additional two years of therapy (Fig. 1) demonstrated OPLL in both the cervical and lumbar regions. There were no neurologic symptoms referrable to these lesions, and detailed neurologic evaluation elicited no signs of impingement on the cervical spinal cord, cauda equina, or spinal nerve roots.

Case 2

A 16-year-old female with ichthyosis was treated with 13-cisretinoic acid for one year, resulting in the development of small hyperostoses at the anterior aspect of multiple vertebral bodies in the cervival and thoracic spine [4]. Following an additional year of retinoid therapy, OPLL at its attachment to $\mathrm{C}-4$ was observed (Fig. 2), without neurologic sequelae.

\section{Discussion}

Although OPLL is a fairly common finding in patients with idiopathic skeletal hyperostosis [12], in some patients OPLL may represent a distinct pathologic entity [8] and can result in spinal cord compression [7], particularly when associated with 

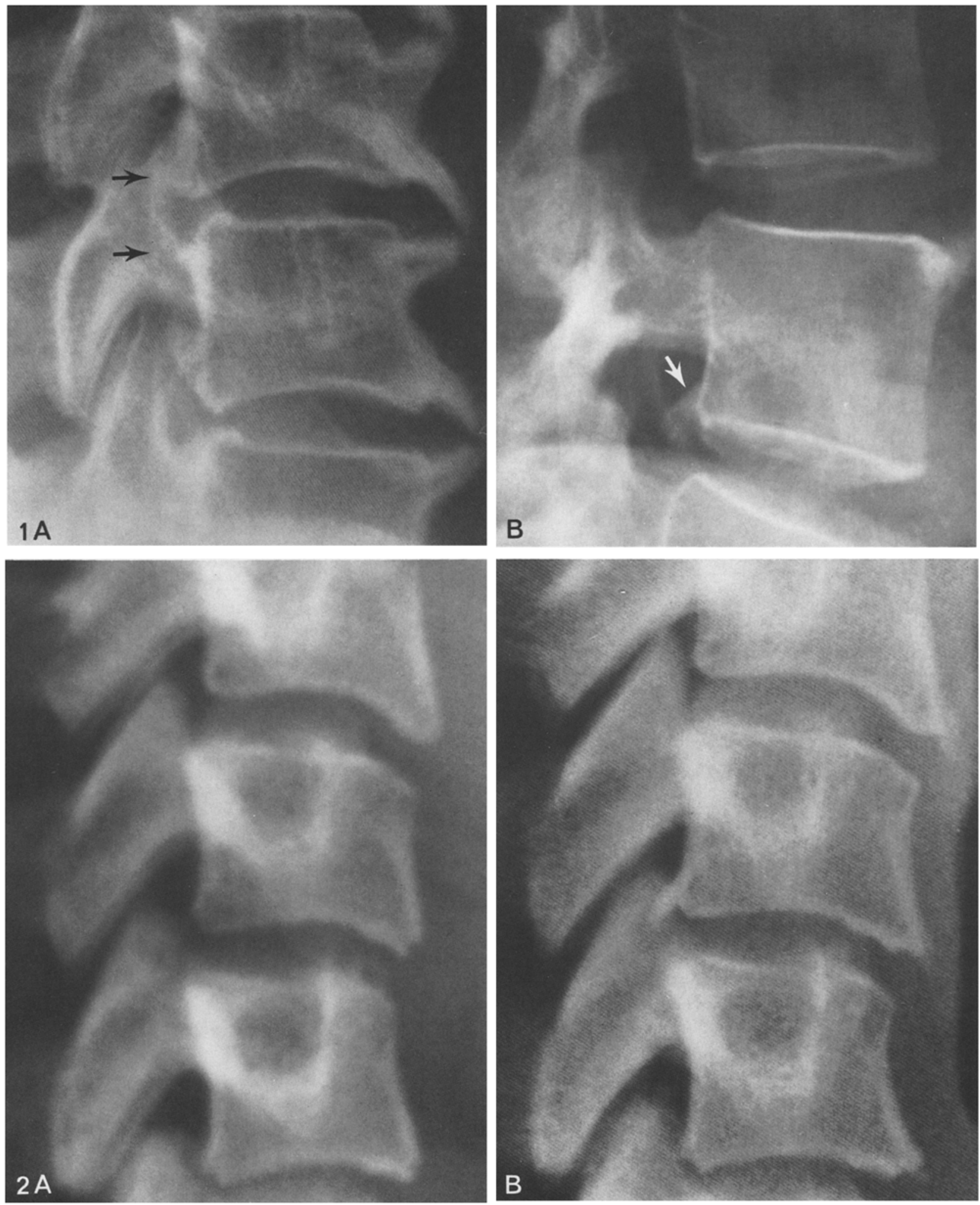

Fig. 1A, B. Case 1. Retinoid-induced ossification of the posterior longitudinal ligament. A Lateral view of the lower cervical spine shows ossification of the posterior longitudinal ligament (arrows). Large hyperostoses arise from the anterior margins of the vertebral bodies. B Detail of the lumbar spine, lateral view demonstrates ossification of the posterior longitudinal ligament at its attachment to L4 (arrow). A hyperostosis arises from the anterior margin of the vertebral body

Fig. 2A, B. Case 2. Interval development of posterior longitudinal ligament ossification during retinoid treatment. A Lateral view of normal cervical spine before therapy. B After two years of therapy, ossification of the posterior longitudinal ligament at its attachment to C-4 has occurred. Hyperostoses arise from the anterior margins of the vertebral bodies 
congenital or acquired narrowing of the spinal canal.

Similarities between idiopathic skeletal hyperostosis and the retinoid-induced skeletal abnormalities have been noted [9]. This observation, as well as the finding of higher unbound retinol levels in patients with idiopathic skeletal hyperostosis [2], suggests that altered vitamin A metabolism may be, responsible in part, for the development of idiopathic skeletal hyperostosis $[1,10]$. In this context, idiopathic skeletal hyperostosis is characterized by more prominent ossification of the anterior longitudinal ligament with a lesser degree of involvement of the posterior longitudinal ligament [5], and this pattern of ossification is also found in the retinoid-induced hyperostotic lesions.

The degree of narrowing of the spinal canal secondary to ossification of the posterior longitudinal ligament necessary to produce neurologic symptoms is greater than that present in our patients [8]. Of importance, however, is the observation that retinoid-induced skeletal hyperostoses can appear following cessation of treatment [3], suggesting a delay in ossification of previously formed lesions [9]. Under these circumstances, we believe that patients on long-term retinoid therapy should be evaluated clinically as well as radiographically, since the actual extent of narrowing of the spinal canal may not be apparent on radiographs.

\section{References}

1. Abiteboul M, Arlet J (1985) Retinol-related hyperostosis. (Letter to the editor.) AJR 144:436

2. Arlet J, Abiteboul B, Mazieres B, Laffont F, Dedieu-Snapir G, Fauvel JM (1983) Vitamin A et hyperostose vertebrale ankylulosante. Rev Rhum Mal Osteoartic 50:63

3. Caffey J (1951) Chronic poisoning due to excess of vitamin A. AJR 65:12

4. Ellis CN, Madison KC, Pennes DR, Martel W, Voorhees JJ (1984) Isotretinoin therapy is associated with early skeletal radiographic changes. J Am Acad Dermatol 10: 1024

5. Forestier J, Lagier R (1971) Ankylosing hyperostosis of the spine. Clin Orthop 74:65

6. Gerber A, Raab AP, Sobel AE (1954) Vitamin A poisoning in adults: With description of a case. Am J Med 16:729

7. Hiramatsu Y, Nobechi T (1971) Calcification of the posterior longitudinal ligament of the spine among Japanese. Radiology $100: 307$

8. Ono K, Ota H, Tada K, Hamada H, Takaoka K (1977) Ossified posterior longitudinal ligament. Spine 2:126

9. Pennes DR, Ellis CN, Madison KC, Voorhees JJ, Martel W (1984) Early skeletal hyperostoses secondary to 13-cisretinoic acid. AJR 141:979

10. Pennes DR, Martel W (1985) Retinol-related hyperostosis. (Reply, Letter to the editor.) AJR 144:436

11. Pittsley RA, Yoder FW (1983) Retinoid hyperostosis: Skeletal toxicity associated with long-term administration of 13-cis-retinoic acid for refractory ichthyosis. N Engl J Med $308: 1012$

12. Resnick D, Guerra J, Robinson CA, Vint VC (1978) Association of diffuse idiopathic skeletal hyperostosis and calcification and ossification of the posterior longitudinal ligament. AJR 131:1049 